\title{
TERRITÓRIOS DE VIDA E DE ESPERANÇA NOS ACAMPAMENTOS FORTALEZA E RENASCER NA MESORREGIÃO SUDESTE DE MATO GROSSO, BRASIL
}

\section{LIFE TERRITORIES AND HOPE IN FORTALEZA AND RENASCER CAMPS IN THE SOUTHEASTERN REGION OF MATO GROSSO}

\author{
Shirlei Fernandes de Oliveira Miyashiro \\ Mestre em Geografia - Programa de Pós-Graduação em Geografia, \\ Universidade Federal de Mato Grosso (UFMT) - Campus Rondonópolis \\ shirleimiyashiro@gmail.com
}

Nestor Alexandre Perehouskei Prof, Dr. do curso de Graduação e Pós-Graduação em Geografia da UFMT - Campus Rondonópolis nestoralexandre34@gmail.com

\section{Resumo}

Esta pesquisa apresenta algumas discussões fundamentadas na lógica da organização dos acampamentos de sem-terra, entendida como lugar de resistência, ou seja, a reativação das ações desses trabalhadores rurais. Os discursos sobre a organização social dos acampamentos tem sido preocupação de vários segmentos, disciplinas e órgãos governamentais ou não. Foram visitados e mapeados os acampamentos Fortaleza no município de Guiratinga e Renascer no município de Pedra Preta, ambos localizados na mesorregião sudeste do estado de Mato Grosso, onde foi aplicado um questionário que buscou identificar o perfil do acampado, bem como compreender a lógica dos fluxos de pessoas que, mesmo morando no acampamento, estabelece certa mobilidade entre o rural e o urbano. Dos 18 entrevistados, 10 $(55,5 \%)$ residem constantemente no acampamento, enquanto $8(44,4 \%)$ são itinerantes. Nesta ótica $15(83,3 \%)$ concordam com este fluxo, principalmente pela necessidade de trabalho; a renda mínima das atividades no acampamento e para a melhoria de qualidade de vida. Nesta perspectiva o acampamento configura-se como um território provisório, ou seja, um território de vida e esperança, que busca na concretização do assentamento, a transformação social.

Palavras-chave: Acampamento. Movimento Social. Reforma Agrária. Território. Luta pela terra.

\begin{abstract}
This research presents some discussions based on the logic of the organization of the camps of landless, understood as a place of resistance, that is, the reactivation of the actions of these rural workers. The discourse on the social organization of the camps have been a concern of several segments, disciplines and government agencies or not. They were visited and mapped the Fortaleza camps in the city of Guiratinga and Renascer in the city of Pedra Preta, both located in the southeastern region of the state of Mato Grosso, where it was applied a questionnaire that sought to identify the encamped profile and understand the logic of flows of people, even living in the camp, establishes certain mobility between rural and urban. Of the 18 respondents, $10(55.5 \%)$ reside constantly in the camp, while $8(44.4 \%)$ are itinerant. In this light $15(83.3 \%)$ agree with this flow, mainly by the need to work; the minimum income
\end{abstract}


from activities in the camp and to improve quality of life. In this perspective the camp appears as a temporary territory, is a territory of life and hope, which seeks the achievement of the settlement, the social transformation.

Keywords: Camping. Social Movement. Land Reform. Territory. Struggle for land.

\section{Introdução}

As principais discussões do presente trabalho são fundamentadas na lógica da organização dos acampamentos ${ }^{1}$ de sem-terra, entendida como lugar de resistência, ou seja, a reativação das ações desses trabalhadores rurais. Os discursos sobre a organização social dos acampamentos tem sido preocupação de vários segmentos, disciplinas e órgãos governamentais ou não. Dentre os acampamentos visitados estão o Fortaleza no município de Guiratinga e o Renascer no município de Pedra Preta, ambos localizados no estado do Mato Grosso, onde observa-se que, os trabalhadores não são somente os que ali vivem, visto que muitos estão dentro e fora do acampamento, configurando-se, dessa forma, em novo arranjo de acampamento de sem-terra.

O acampamento representa o início da luta deste grupo social para conquistar os seus "pedaços de terra", que de acordo com Fernandes (2007), são espaços e tempos de transição na luta pela terra. São, por conseguinte, realidades em transformação, tanto para as famílias de sem-terra que estão do lado de fora quanto para as famílias que estão no acampamento e, praticamente não contam com apoio governamental, vivendo umas dependendo das outras, sendo esta solidariedade, segundo Vendramini (2002), manifestada por entidades, organizações e várias pessoas que assumem o papel de lideranças, viabilizando condições para o acampamento sobreviver, material e psicologicamente. Na perspectiva de unidade entre os acampados, Heidrich (2000, p. 60) expressa que,

\footnotetext{
[...] o acampamento produz formas de experiências de si onde os acampados tornam-se sujeitos de um modo particular. Essas formas de experiência configuram a formação da subjetividade socioespacial (ou territorial), na qual o sentimento de pertencimento a um lugar não é fixo (mas que se encontra no discurso do movimento), mas criado e recriado por seus acampados onde estiverem reunidos [...] (HEIDRICH, 2000, p. 60).
}

A importância da terra está relacionada ao valor, necessidade e segurança. A organização de uma ocupação decorre da necessidade familiar e acontece pela consciência 
construída na realidade em que se vive, ou seja, é uma construção histórica. Por isso, um aprendizado no processo histórico de construção das experiências de resistência, conforme descrevem Gancho, Lopes e Toledo (1991, p. 5),

[...] a terra pode significar riqueza ou pobreza, vida ou morte, poder político e posição social ou marginalização. Para cada pessoa ou grupo social ela tem um valor. [...] A terra exerce (sempre exerceu) atração sobre o homem: ela não é apenas sinônimo de riqueza e de poder, mas também a posse da terra, [...] investida de ideias de segurança na vida e até mesmo na morte (GANCHO; LOPES; TOLEDO, 1991, p. 5).

Nesta ótica, a experiência tem a sua lógica construída na práxis, pois, de acordo com Vendramini (2002, p. 86), "são diferentes os significados de cada experiência: a preparação para a ocupação, por exemplo, é um momento difícil para toda família, sobretudo para os adultos, pois lhes cabe a decisão sobre quando, como e se realmente desejam participar da ocupação", ou seja, essa lógica tem como componentes constitutivos a indignação e a revolta, a necessidade e o interesse, a consciência e a identidade, a experiência e a resistência, o movimento e a superação, a concepção de "terra de trabalho" contra a concepção de "terra de negócio e de exploração"2.

O termo "terra de trabalho" expressa que o pequeno proprietário usa somente a mão de obra familiar para o trabalho na terra, onde "os seus ganhos são do seu trabalho e o trabalho de sua família, e não ganhos de capitais, exatamente porque estes ganhos não provem de um capitalista sobre um trabalhador expropriado dos seus instrumentos de trabalho" (MARTINS, 1981, p. 59). Ele ainda discute o termo "terra de negócio", afirmando que,

[...] quando o capitalista se apropria da terra ele o faz com o intuito do lucro, direto ou indireto. $\mathrm{Ou}$ a terra serve para explorar o trabalho de quem não tem a terra; ou a terra serve para ser vendida por alto preço a quem dela precisa para trabalhar e não a tem (MARTINS, 1981, p. 60).

Por isso, nem sempre a apropriação da terra pelo capital se deve à vontade do capitalista se dedicar à agricultura. Diferentemente, o espaço escolhido para ser o acampamento, não é o espaço tratado a partir da Geografia dos solos, e sim, da sociedade: um espaço que permite sua transformação a serviço da comunidade. Neste contexto, Santos (1977, p. 8) afirma que "a história não se escreve fora do espaço, e não há sociedade sem espaço. O espaço, ele mesmo é social". Stédile (1997, p. 25) complementa que "basta percorrer o interior do país para se deparar com os enormes contingentes de deserdados do 
campo, que ainda dependem da terra para sua sobrevivência". Com base nesta ideia é fundamental o acompanhamento e o estudo sobre a realidade das famílias acampadas, na perspectiva de uma ordem social justa e igualitária.

A família vista no acampamento nem sempre é composta de todos os membros: pai, mãe e filhos, ou seja, a família tradicional. Nesses espaços de luta alguns membros vivem sozinhos, como homens e mulheres ou idosos, sem companheiros, sendo observada também uma parcela de mulheres que vivem apenas com os filhos, bem como avós que criam seus netos e, dessa forma, constituem novos modelos familiares. Neste sentido, Biroli (2014) afirma que a estrutura familiar está ligada a afetos e sentimentos, de diferentes tipos e se define conforme normas, práticas e valores que têm seu lugar, tempo e história, dentro de cada unidade familiar, por isso, o acampamento de sem-terra se configura em um espaço onde todos os componentes fazem parte de uma grande família, separada e unida ao mesmo tempo, na busca de um ideal único.

Definidos os contornos do "espaço de luta e de resistência" representado pelo acampamento, falta somente a decisão de quando ocupar. É com a ocupação que os trabalhadores sem-terra vêm a público e dimensionam o espaço de socialização e sociabilidade política, intervindo na realidade, acampando nas margens das rodovias, organizando a ocupação, construindo, enfim, o seu espaço de luta e resistência.

Como a ação de participar de uma ocupação não é uma decisão tão simples, afinal, mais do que experiência, significa transformar a própria vida, para algumas famílias, existe a indecisão e o medo. Estas inseguranças são geralmente postuladas pelos parentes que acabam questionando se realmente vai dar certo ou não, por isso, segue-se o medo de ir para o acampamento sem saber o que se encontrará, ou mesmo, se será bem acolhido pelos outros componentes do grupo, ou seja, haverá divergências? Encontrarão confrontos por parte da justiça, despejos, expulsões? Como a vida se direcionará a partir desta busca?

Estes são alguns dos principais pontos a serem analisados sobre os trabalhadores rurais sem-terra que aderiram pela vivência no acampamento e, para superar temores, é necessário confiança nas pessoas que compõem e coordenam o Movimento dos Trabalhadores Acampados e Assentados (MTA). Neste universo de estudo, os acampamentos existentes são coordenados por lideranças filiadas a este movimento, configurando-se dessa forma, os seguintes acampamentos: Acampamentos Fortaleza e Renascer, ambos do Movimento dos Trabalhadores Acampados e Assentados. 
A liderança do acampamento tem responsabilidade ao defender a ocupação, bem como de apresentar ideias e referências que permitam a superação das dúvidas, desenvolvendo argumentos nas reuniões, para o dimensionamento do espaço de socialização e sociabilidade política. Todavia, muitos ficam atentos e só seguirão para o acampamento, depois de efetivada a ocupação.

$\mathrm{O}$ medo e a insegurança sentidos ao aderirem a um movimento social requer coragem das famílias e, acima de tudo, esperança em conseguir um futuro melhor, que deverá ser incessante, até a plenitude de sua realização, que se concretizará na aquisição de um lote de assentamento estruturado, proporcionando neste núcleo, renda e crescimento econômico. Enfatizando os assentamentos, Duqué e Caniello (2004) os definem como espaços diferenciados de relação com o Estado e, é essa distinção que faz existir o assentamento e, por consequência, os assentados. Neste sentido, Bergamasco e Norder (1996, p. 7) contribuem com a seguinte visão do assentamento rural, dizendo que, estes,

[...] podem ser definidos como a criação de novas unidades agrícolas, por meio de políticas governamentais visando o reordenamento do uso da terra, em benefício de trabalhadores rurais sem-terra ou com pouca terra. Como o seu significado remete à fixação do trabalhador na agricultura, envolve também a disponibilidade de condições adequadas para o uso da terra e o incentivo a organização social e a vida comunitária (BERGAMASCO; NORDER, 1996, p. 7).

Desta forma, conhecer a construção social desses acampamentos, como a organização de suas comunidades, anseios, indignações, arranjos e possíveis dinâmicas, justificam a importância deste estudo, que buscará verificar a realidade atual do grupo, tradicionalmente excluído e que tem a contribuir com seus conhecimentos e experiências de vida para a sociedade.

\section{A vida e a esperança na dinâmica territorial}

Um território pode ser visto sob a forma de lugar. Segundo Callai (2000, p. 121), "um lugar apresenta como uma das suas características a linearidade da ocupação - a sua horizontalidade - a expansão do uso do solo a partir de atividades específicas de cada lugar”. Desta forma, então, um espaço ocupado pelo sem-terra se torna para si o lugar/território e, significa muito mais que o sentido geográfico de localização, valorizando-se os tipos de experiência, as necessidades e a segurança (RELPH, 1979). 
No que se refere ao conceito de território, vários autores se destacam, distinguindo-o de espaço.

Para Raffestin (1980, p. 59), o espaço é anterior ao território e o território se forma a partir do espaço onde se projetou um trabalho, seja energia e informação, em que se revelam as relações de poder, isto é, o "território é o espaço político por excelência, o campo de ação dos trunfos".

Já Souza (2005, p. 79) se contrapõe às ideias de Raffestin discutindo que o território é definido e delimitado como um espaço a partir da relação de poder, indiferente de sua gênese (recursos naturais, identidade e cultura). Isto é, "quem domina ou influencia e como domina ou influencia esse espaço?" Nos traz a ideia de existir, no mesmo espaço, territórios com funções diferentes nas diferentes escalas espaciais e temporais.

O primeiro autor trabalha a partir da concepção da natureza do espaço, enquanto o segundo o determina a partir das relações de poder.

Para Fernandes (2008, p. 4) a formação de territórios é sempre um processo de fragmentação do espaço. Essa fratura se dá com base na intencionalidade. Para ele, "os territórios podem ser vistos de diversas formas, por diferentes sujeitos. Dar significados mais amplos ou mais restritos depende da intencionalidade do sujeito que elabora e/ou que usa o conceito". Diante disso, o fato é que o território deixou de ser visto apenas enquanto essência do Estado.

Nos territórios de luta pelos sem-terra, tem-se na ocupação a forma de apropriação de um espaço que, anteriormente, apresentava-se com pouca ou nenhuma utilização, e, posteriormente, apreende-se a partir da busca de uma identidade e de um existir. Nestas experiências de ordenamento territorial, empreendidas por grupos sociais culturalmente diferenciados, possibilitam-se espaços de discussão onde os posicionamentos dos atores sociais saem da invisibilidade, para se expressarem como uma voz destoante do padrão mercadológico que pauta a apropriação do espaço.

$\mathrm{Na}$ vivência, o significado de espaço frequentemente se funde com o de lugar, pois, o que antes era indiferente para a maioria, passa a ter relevância para os que estão embaixo da lona. Para Tuan (1983), o lugar é uma área que foi apropriada afetivamente, transformando um espaço indiferente em lugar, o que por sua vez implica na relação com o tempo de significação deste espaço em lugar. Portanto, "o lugar é um mundo de significado organizado" (TUAN, 1983, p. 198). 
A discussão a respeito do conceito de território apresentada até o momento busca estabelecer um diálogo com a ideia de territórios provisórios, estabelecida com a existência de acampamentos em território capitalista, para, posteriormente, adentrar na ideia de "território de esperança", como indicam Moreira e Targino (2007). É importante ressaltar que o poder do Estado, utiliza-se de seus órgãos institucionais para imprimir um modelo dominante, conforme propõe Oliveira (1988, p. 74) sobre o conceito de território que,

[...] deve ser apreendido como síntese contraditória, como totalidade concreta do processo/modo de produção/distribuição/circulação/consumo e suas articulações e mediações supraestruturais em que o Estado desempenha a função de regulação. $\mathrm{O}$ território é assim produto concreto da luta de classes travada pela sociedade no processo de produção de sua existência [...] (OLIVEIRA, 1988, p. 74).

Com estes pressupostos, o conceito "território de esperança" parte da preocupação em entender a diferença existente entre as porções do espaço não-produtivo, definidas de um modo geral como "território", buscando, com isso, diferenciá-los como espaços de luta pela terra e pela sobrevivência nela conquistada, com uso de novas possibilidades de acesso pela via institucional.

Nesse sentido, as escalas geográficas particulares e dos territórios sociais apontam para uma variedade de maneiras de viver, de se relacionar com os elementos naturais, além de peculiaridades políticas e culturais, que contrariam o fluxo linear da constituição territorial e, por conseguinte, sinalizam para a existência, segundo Harvey (2009, p. 11), de "desenvolvimentos geográficos desiguais", ou seja, os acampamentos surgem de maneira desigual dentro dos espaços, não sendo organizados por uma lógica do espaço geográfico, e sim, a partir das necessidades e materialização da luta pela terra.

Neste universo Moreira e Targino (2007, p. 8) constroem o conceito de "Território de Esperança", como sendo,

[...] aquele conquistado e construído: pela luta de ocupação de terra, promovida pelos trabalhadores sem terra; pela luta de consolidação das diferentes formas de agricultura. $\mathrm{Na}$ verdade, trata-se de um novo território, construido com base na utopia e na esperança, "Território de Esperança" [...] carregado de contradições, mas também de sinalizações de uma forma experienciada de organização social. Desse modo, "Território de Esperança" representa a superação do "Território de Exploração" (MOREIRA; TARGINO, 2007, p. 8).

A ideia de "território de esperança" ainda se encontra em construção. Para Moreira e Targino (2007, p. 4) corresponde tanto à porção do espaço "conquistado e construído pelas 
lutas de resistência e de ocupação promovidas pelos trabalhadores sem-terra, como aquela resultante da luta de resistência, recriação e consolidação das diferentes formas de agricultura camponesa".

Assim, ainda de acordo com Moreira e Targino (2007, p. 4) o acampamento de reforma agrária seria uma fração do "território de esperança", o qual

[...] não se trata, pois, de um território fruto de uma ruptura promovida por um processo revolucionário, mas pode se constituir numa possibilidade transformadora. Por isto ele só pode ser entendido como parte integrante de um processo. Daí o Território de Esperança se constituir num território em movimento, vivo, que experiencia um processo contínuo de (re) criação, (re) definição, (re) delimitação. Território inacabado, por conseguinte, sujeito a contradições, avanços, retrocessos, ganhos e perdas (MOREIRA; TARGINO, 2007, p. 4).

Nesta ótica, as desigualdades de ocupação do espaço geográfico discutidas a partir das concepções de Harvey, parametrizadas nas particularidades dos grupos sociais em busca de conquista da terra, ressoam nas discussões de Moreira e Targino, que apresentam o conceito de "territórios de esperança", ou seja, espaços de resistência que, a partir da ocupação e das relações estabelecidas pelo grupo, vão determinando territorialidades que transformam o espaço geográfico definido, anteriormente, na lógica do capital, que tende a excluir essa recriação do território definida nos sonhos e na utopia.

Para se compreender o que se passa em um acampamento de sem-terra, onde diferentes pessoas almejam um objetivo comum, ou seja, a posse da terra, fez-se necessário recuperar e discutir diferentes concepções de território. Ao se unirem durante os períodos de acampamento, em área específica, as famílias sem-terra, juntamente com o movimento MTA, envolvidas no processo de luta pelo acesso a frações do território dominado pelo capital, discutem as possibilidades de uso da terra, no intuito de construir moradias e plantar alimentos, e, assim, transformar um pedaço de terra em um território de esperança e, com isso, mostram-se prósperos por adquirirem um pedaço de chão que, num futuro, espera-se próximo, poderá ser definido como um território definitivo.

Portanto, a ideia de posse da terra, para os sem-terra, é diferente da concebida pela lógica capitalista. Enquanto para o sem-terra, a posse da terra representa a possibilidade de ter onde morar, produzir e garantir a subsistência familiar; para os capitalistas, a posse tem como meta transformar a terra em máquina lucrativa a serviço da reprodução do capital. 
O grande entrave que desestabiliza a organização dos sem-terra na fase de acampamento encontra-se, justamente, no longo período de espera, ao qual são obrigados a se submeter (na maioria dos casos, morar) próximos à área pela qual estão lutando. Muitas das famílias desistem e os que optaram por ficar, resistem aos impasses e dificuldades. Assim, o conceito de "Territórios de Esperança" que está sendo construído, pode ser aplicado no âmbito da pesquisa realizada, pois o acampamento nasce da resistência dos sem-terra em permanecerem na terra onde vivem e trabalham.

Mesmo com a justiça se posicionando favorável aos interesses do latifúndio, a união dos sem-terra é vital para a conquista da terra. Nessa perspectiva geográfica, o conceito de território possibilitou o entendimento sobre a disputa entre propriedade privada e propriedade camponesa, bem como sobre a luta entre capital e trabalho no campo. O território, portanto, pressupõe relações sociais de poder, por isso, os acampamentos de sem-terra são considerados como ponto inicial na luta pela terra, onde famílias se organizam em busca de um recomeço e de uma nova perspectiva de vida.

Nesta perspectiva, os objetivos desta contribuição são de caracterizar o acampamento de trabalhadores rurais sem-terra como "território provisório" para o assentamento definitivo das famílias, explicando a atual organização dos trabalhadores rurais na luta pela terra e no trabalho do campo, bem como entendendo a lógica de fluxos de população estabelecidos a partir de certa tendência à minimização do número de famílias nos acampamentos.

Esta pesquisa parametrizada nos conceitos de território, no sentido de movimento e, por isso, fundamentada na dinâmica dos territórios de vida e de esperança, buscará investigar o perfil socioeconômico desses atores sociais, bem como suas dinâmicas territoriais em busca da concretização de seu espaço definitivo.

\section{Materiais e métodos}

Destaca-se na presente pesquisa, o uso do conceito "território de esperança" que permitiu identificar de forma objetiva o cotidiano do sem-terra, na busca de realizar seus sonhos em relação à posse de um lote, com o intuito de construir moradias e poder desenvolver suas atividades com segurança e dignidade, e, assim, transformar um pedaço de terra que poderá ser um território definitivo. 
Esta pesquisa foi desenvolvida em dois acampamentos do Movimento dos Trabalhadores Acampados e Assentados (MTA), sendo o acampamento Fortaleza localizado às margens da rodovia BR-364 no município de Pedra Preta e o acampamento Renascer na MT-270, no município de Guiratinga, ambos localizados na Mesorregião Sudeste. Foram realizadas entrevistas com 18 moradores e participantes do movimento que residem com suas famílias em um sistema comunitário, compartilhando suas necessidades, dificuldades e anseios de um futuro melhor.

A escolha desses dois acampamentos se efetivou, primeiramente, por ambos se localizarem próximos ao município de Rondonópolis, e, posteriormente, por pertencerem ao MTA.

A investigação foi pautada numa abordagem quanti-qualitativa, a partir da realização de trabalhos de campo, com visitas in loco aos locais dos acampamentos, nos dias 12 e 13 de julho de 2014; 06 e 07 de setembro de 2014; 11 de outubro de 2014 e 22 de novembro de 2014, num total de 6 visitações. Foram entrevistadas as pessoas que estavam presentes nesses acampamentos nas datas descritas.

Nesse período foram aplicados 18 questionários, cujas questões buscaram identificar o perfil socioeconômico dos envolvidos, bem como aspectos específicos que revelaram a dinâmica do cotidiano dos acampamentos. Todavia, parte de seus moradores não se encontravam nos respectivos espaços, pois algumas das visitas realizadas ocorreram em dias de feriado e, em dias de reuniões organizadas pelas lideranças do acampamento na cidade.

De acordo com os relatórios do MTA, existem 217 cadastrados no acampamento Fortaleza e 78 no acampamento Renascer, no entanto, não se obteve dados concretos do total de famílias que frequentam o acampamento. No total, foram entrevistados 18 pessoas, sendo 11 no acampamento Fortaleza e 7 no acampamento Renascer.

Para determinar a amostra de sem-terra em acampamento que representa um conjunto de elementos com características comuns, foi adotado o número total de moradores disponíveis nos acampamentos nos dias escolhidos para as atividades de campo.

Para delimitar os espaços de luta dos acampados, foram realizadas visitas aos acampamentos para coleta de pontos (coordenadas geográficas), possibilitando a construção de um banco de dados para a elaboração de mapas de símbolos pontuais. Nestas visitas foram identificados os pontos utilizando o Global Positioning System (Sistema de Posicionamento 
Territórios de vida e de esperança nos acampamentos Fortaleza e Renascer na Mesorregião Sudeste de Mato Grosso, Brasil
Shirlei Fernandes de Oliveira Miyashiro Nestor Alexandre Perehouskei

Global) - aplicativo GPS Essentials. Foi realizado mapeamento das áreas de estudo utilizando-se dos programas TerraView, versão 4.2.2 e ArcView, versão 3.2.

Na elaboração do mapa no software TerraView utilizou-se os dados em formato vetorial adquiridos no Instituto Brasileiro de Geografia e Estatística (IBGE), obtendo-se mapas dos limites nacionais, regionais, estaduais e municipais; mapas de localização das sedes dos municípios e do estado de Mato Grosso.

Também em formato vetorial obteve-se dados sobre os assentamentos no Incra, bem como a representação das rodovias desta área no Departamento Nacional de Infraestrutura e Transporte (DNIT).

A disposição dos pontos nesses mapas cria uma regionalização do espaço, representando os acampamentos de sem-terra.

\section{A vida real dos acampados e as experiências}

Ao buscar o conhecimento sobre os sem-terra na mesorregião de Rondonópolis, depara-se com dois lugares que chamam a atenção ao passar pela rodovia BR-364, o acampamento Fortaleza, localizado no município de Pedra Preta, Mato Grosso e, às margens da rodovia MT-270, o acampamento Renascer, localizado no sentido do município de Guiratinga, Mato Grosso. A formação de acampamentos às margens dessas rodovias foi um artifício utilizado pelo MTA, pois, para os sem-terra, não havia outras opções, senão ocupar estes espaços.

Existem vários fatores que contribuíram para a constituição dos acampamentos nesses espaços, dentre estes, alguns componentes advindos de outros acampamentos que se tornaram novos assentamentos, ou seja, pessoas ligadas às famílias dos sem-terras e, alguns que encontraram no acampamento certo auxílio para atender as suas necessidades. Sendo assim, formaram novos acampamentos, como o Fortaleza e Renascer.

A Figura 01 demonstra o município de Pedra Preta, Mato Grosso, que pertence à mesorregião sudeste de Mato Grosso, localizado no fuso 21, nas seguintes coordenadas geográficas, Latitude: $16^{\circ} 36^{\prime} 41^{\prime \prime}$ Sul e Longitude: 54²7'34' Oeste. Mostra também a sede municipal, aproximadamente a $32 \mathrm{~km}$ do município de Rondonópolis. Foram destacadas três importantes rodovias, sendo a rodovia BR-364 a de maior importância, pois corta o município 
Territórios de vida e de esperança nos acampamentos Fortaleza e Renascer na Mesorregião Sudeste de Mato Grosso, Brasil
Shirlei Fernandes de Oliveira Miyashiro Nestor Alexandre Perehouskei

quase ao meio onde localiza-se o acampamento Fortaleza, coordenado pelo movimento social MTA, sendo um dos mais antigos na questão da luta pela terra.

Figura 01: Mapa de localização do município de Pedra Preta, Mato Grosso

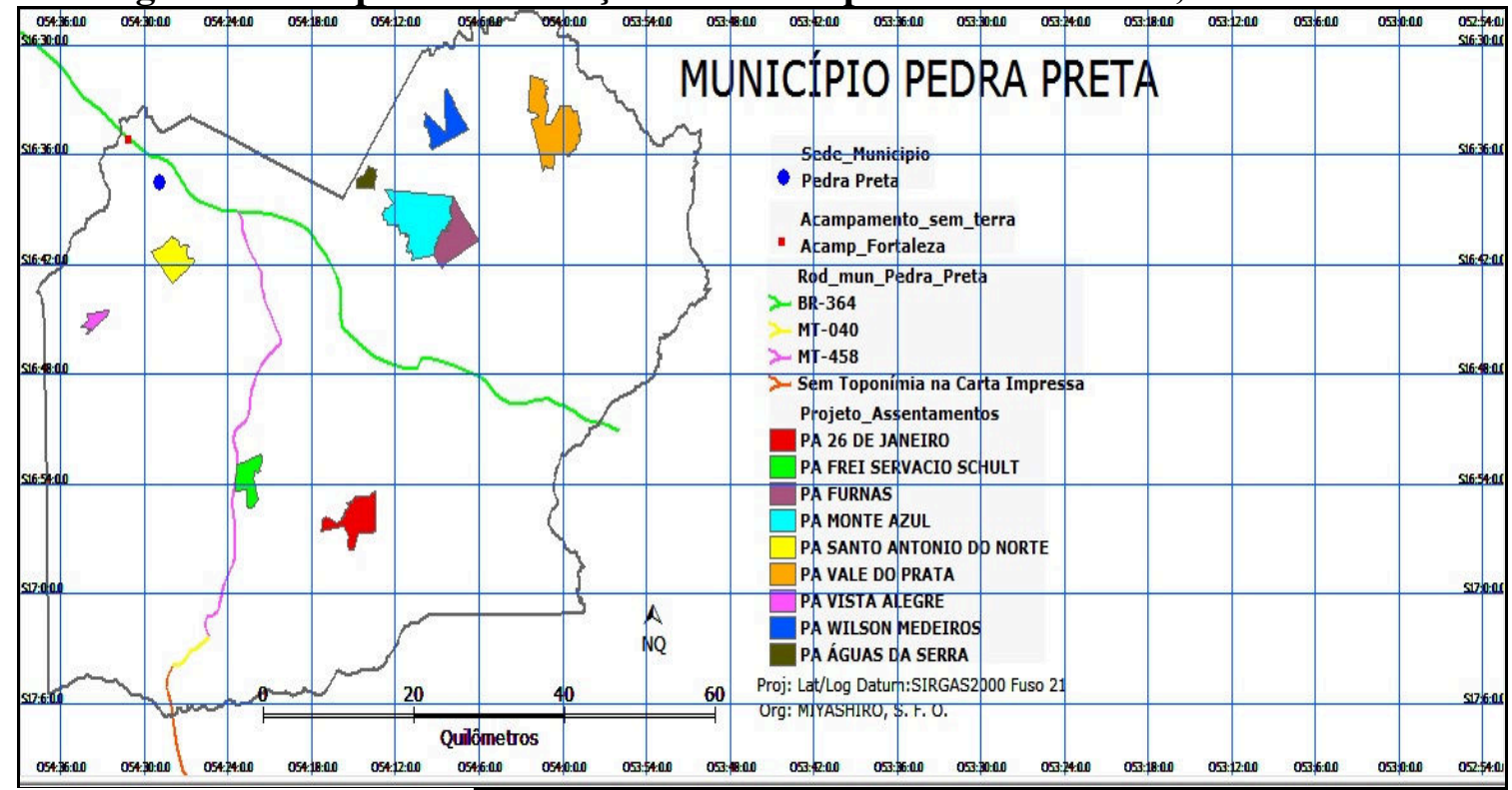

Fonte: IBGE/DNIT/INCRA (2014).

Org.: MIYASHIRO, S. F. O. (2015).

Figura 02: Mapa de localização do município de Guiratinga, Mato Grosso

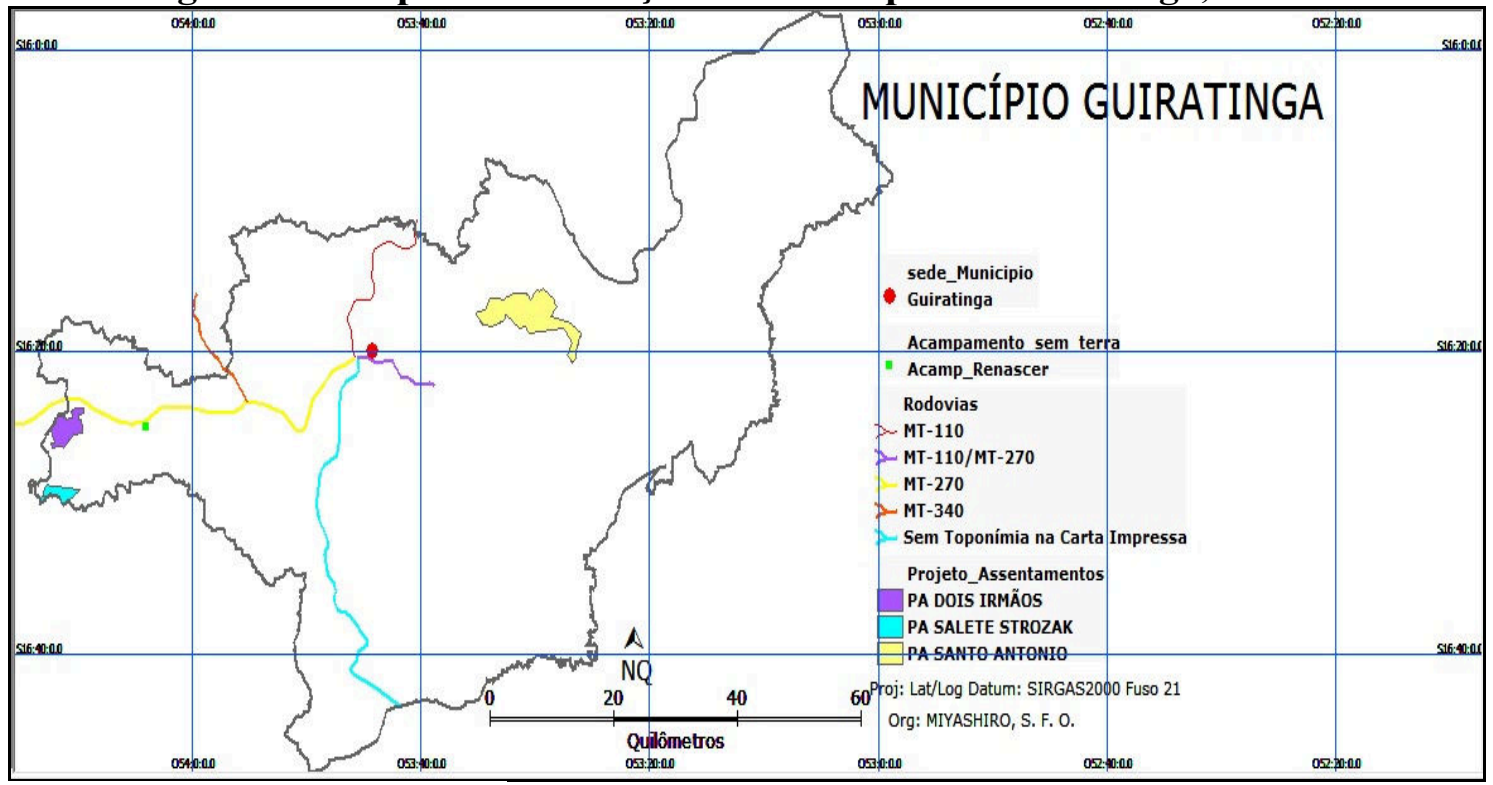

Fonte: IBGE/DNIT/INCRA (2014).

Org.: MIYASHIRO, S. F. O. (2015).

A Figura 02 demonstra a localização do acampamento Renascer em Guiratinga, Mato Grosso, que é marcado pela agricultura familiar, cuja sede municipal fica 
Territórios de vida e de esperança nos acampamentos Fortaleza e Renascer na Mesorregião Sudeste de Mato Grosso, Brasil
Shirlei Fernandes de Oliveira Miyashiro Nestor Alexandre Perehouskei

aproximadamente a 112 quilômetros da cidade de Rondonópolis, tornando-se o maior consumidor do que é produzido pelas famílias assentadas.

Nestes acampamentos a pesquisa foi pautada numa abordagem quanti-qualitativa, que possibilitou demonstrar, através de uma amostra de entrevistados, a priori, uma análise socioeconômica, com ênfase no perfil do acampado.

\section{Perfil socioeconômico dos acampados}

Neste sentido, a primeira questão do perfil socioeconômico refere-se ao sexo dos entrevistados.

Tabela 01: Número de pessoas $\left(\mathbf{N}^{\circ}\right)$ e percentual (\%) segundo sexo dos entrevistados nos acampamentos Fortaleza e Renascer, Mato Grosso

\begin{tabular}{|c|c|c|c|c|c|c|}
\hline \multicolumn{7}{|c|}{ Sexo } \\
\hline & \multicolumn{2}{|c|}{ Masculino } & \multicolumn{2}{|c|}{ Feminino } & \multicolumn{2}{|c|}{ Total } \\
\hline Acampamento & $\mathrm{N}^{\mathrm{o}}$ & $\%$ & $\mathrm{~N}^{\mathrm{o}}$ & $\%$ & $\mathrm{~N}^{\mathrm{o}}$ & $\%$ \\
\hline Fortaleza & 7 & 58,3 & 4 & 66,6 & 11 & 61,1 \\
\hline Renascer & 5 & 41,7 & 2 & 33,4 & 7 & 38,9 \\
\hline Total & 12 & 100 & 6 & 100 & 18 & 100 \\
\hline
\end{tabular}

Fonte: MIYASHIRO, S. F. O. (2014/2015).

Org.: MIYASHIRO, S. F. O. (2015).

Conforme expressa a Tabela 01, demonstrando que dos 18 indivíduos, equivalente a $100 \%$, a maioria, é do sexo masculino, sendo 7 , equivalente a 58,3\% no acampamento Fortaleza e 5, equivalente a $41,7 \%$ no acampamento Renascer. De acordo com os entrevistados, esta lógica se dá em razão de haver uma preocupação com a segurança do acampamento e ocupação diária no trabalho para a garantia de subsistência, pressupondo a presença masculina, no sentido de imposição em relação à ocupação do lugar. Por sua vez, as mulheres têm uma representação menor, ou seja, 4, equivalente a $66,6 \%$ no acampamento Fortaleza e 2, equivalente a 33,4\% no Renascer, devido principalmente ao fato de muitas ficarem nas cidades, para cuidar dos filhos e outros afazeres domésticos.

A segunda questão do perfil socioeconômico refere-se à faixa etária dos entrevistados, conforme expressa a Tabela 02, revelando o perfil dos moradores nos acampamentos Fortaleza e Renascer. 
Territórios de vida e de esperança nos acampamentos Fortaleza e Renascer na Mesorregião Sudeste de Mato Grosso, Brasil
Shirlei Fernandes de Oliveira Miyashiro Nestor Alexandre Perehouskei

Tabela 02: Número de pessoas $\left(\mathrm{N}^{\circ}\right)$ e percentual (\%) da faixa etária dos entrevistados nos acampamentos Fortaleza e Renascer, Mato Grosso

\begin{tabular}{|c|c|c|c|c|c|c|c|c|c|c|}
\hline \multicolumn{11}{|c|}{ Faixa etária } \\
\hline \multirow[b]{2}{*}{ Acampamento } & \multicolumn{2}{|c|}{31 a 40} & \multicolumn{2}{|c|}{41 a 50} & \multicolumn{2}{|c|}{51 a 60} & \multicolumn{2}{|c|}{+60} & \multicolumn{2}{|c|}{ TOTAL } \\
\hline & $\mathrm{N}^{\mathrm{o}}$ & $\%$ & $\mathrm{~N}^{\mathrm{o}}$ & $\%$ & $\mathrm{~N}^{\mathrm{o}}$ & $\%$ & $\mathrm{~N}^{\mathrm{o}}$ & $\%$ & $\mathrm{~N}^{\mathrm{o}}$ & $\%$ \\
\hline Fortaleza & 3 & 75 & 1 & 33,4 & 3 & 75 & 4 & 57,1 & 11 & 61,1 \\
\hline Renascer & 1 & 25 & 2 & 66,6 & 1 & 25 & 3 & 42,9 & 7 & 38,9 \\
\hline Total & 4 & 100 & 3 & 100 & 4 & 100 & 7 & 100 & 18 & 100 \\
\hline
\end{tabular}

Fonte: MIYASHIRO, S. F. O. (2014/2015).

Org.: MIYASHIRO, S. F. O. (2015).

Nesta questão, o maior número de entrevistados ocorreu na faixa-etária de mais de 60 anos, sendo 7 pessoas, seguidos da faixa-etária de 31 a 40 anos e 51 a 60 anos, ambas correspondendo a 4 indivíduos cada. Em menor porcentagem, as pessoas que estão na faixaetária de 41 a 50 anos, com 3 indivíduos. Verifica-se o predomínio de pessoas na faixa-etária de 31 a 60 anos, num total de 11 pessoas do total de entrevistados, ou seja, pessoas que ainda se encontram em fases de vida produtiva.

A terceira questão do perfil socioeconômico refere-se ao grau de instrução dos entrevistados, conforme expressa a Tabela 03. Estes dados vêm de encontro com a faixa etária e a situação econômica do acampado, que condiz com a baixa escolaridade e, portanto, a sua baixa remuneração.

Tabela 03: Número de pessoas $\left(\mathrm{N}^{\circ}\right)$ e percentual (\%) do grau de escolaridade dos entrevistados nos acampamentos Fortaleza e Renascer, Mato Grosso Grau de escolaridade

\begin{tabular}{lrrrrrc}
\hline & \multicolumn{2}{c}{ Sem escolaridade } & \multicolumn{2}{c}{ Fundamental } & \multicolumn{2}{c}{ Total } \\
\cline { 2 - 7 } Acampamento & $\mathrm{N}^{\mathrm{o}}$ & $\%$ & $\mathrm{~N}^{\mathrm{O}}$ & $\%$ & $\mathrm{~N}^{\mathrm{O}}$ & $\%$ \\
Fortaleza & 4 & 50 & 7 & 70 & 11 & 61,1 \\
Renascer & 4 & 50 & 3 & 30 & 7 & 38,9 \\
\hline Total & $\mathbf{8}$ & $\mathbf{1 0 0}$ & $\mathbf{1 0}$ & $\mathbf{1 0 0}$ & $\mathbf{1 8}$ & $\mathbf{1 0 0}$ \\
\hline
\end{tabular}

Fonte: MIYASHIRO, S. F. O. (2014/2015).

Org.: MIYASHIRO, S. F. O. (2015).

Com os resultados da Tabela 03, a maioria dos entrevistados estudou no máximo até a $4^{\mathrm{a}}$ série do atual primeiro ciclo do ensino fundamental, que corresponde a 7 indivíduos, equivalente a $70 \%$ no acampamento Fortaleza e, 3 indivíduos, equivalente a 30\% no acampamento Renascer. Nos mesmos locais, um total de 8 entrevistados, equivalente a $50 \%$ em cada acampamento, de pessoas sem escolaridade, concomitantemente, não houve entrevistados que obtivessem o ensino médio. Apesar de pouca escolaridade, são pessoas que trazem como experiência, a vivência e a luta como sinônimos de saber. 
Territórios de vida e de esperança nos acampamentos Fortaleza e Renascer na Mesorregião Sudeste de Mato Grosso, Brasil
Shirlei Fernandes de Oliveira Miyashiro Nestor Alexandre Perehouskei

A quarta questão do perfil socioeconômico refere-se ao número de pessoas por família dos entrevistados, conforme expressa a Tabela 04, prevalecendo as famílias de 2 a 5 pessoas, sendo que a variável de 2 a 3 pessoas correspondeu a 9 entrevistados, equivalente a $50 \%$, e a variável de 4 a 5 pessoas, correspondeu a 7 entrevistados. Em menores porcentagens encontrou-se uma pessoa que mora sozinha, e, também na mesma proporção, uma família com 6 pessoas. Neste universo apresentaram-se famílias com duas a três pessoas, compostas pelo avô, a avó e um neto, que em alguns casos, somente o avô é residente no acampamento, pois os demais membros moram nas cidades circunvizinhas (Pedra Preta e Rondonópolis) para o estudo das crianças. Esta variável se articula com os resultados da Tabela 03 e 04, onde prevaleceram pessoas acima de 60 anos e com baixo nível de escolaridade.

Tabela 04: Número de pessoas $\left(\mathrm{N}^{\circ}\right)$ e percentual $(\%)$ de membros da família por entrevistados nos acampamentos Fortaleza e Renascer, Mato Grosso

\begin{tabular}{lrrrrrrrrrrr}
\hline & \multicolumn{1}{c}{ Número de pessoas na família } \\
\hline & \multicolumn{1}{c}{1} & \multicolumn{1}{c}{2 a 3} & 4 a 5 & \multicolumn{3}{c}{ Total } \\
\cline { 2 - 13 } Acampamento & $\mathrm{N}^{\mathrm{o}}$ & $\%$ & $\mathrm{~N}^{\mathrm{o}}$ & \multicolumn{1}{c}{$\%$} & $\mathrm{~N}^{\mathrm{O}}$ & \multicolumn{1}{c}{$\%$} & $\mathrm{~N}^{\mathrm{o}}$ & $\%$ & $\mathrm{~N}^{\circ}$ & $\%$ \\
Fortaleza & 1 & 100 & 5 & 55,5 & 4 & 57,1 & 1 & 100 & 11 & 61,1 \\
Renascer & 0 & 0 & 4 & 44,4 & 3 & 42,9 & 0 & 0 & 7 & 38,9 \\
\hline Total & $\mathbf{1}$ & $\mathbf{1 0 0}$ & $\mathbf{9}$ & $\mathbf{1 0 0}$ & $\mathbf{7}$ & $\mathbf{1 0 0}$ & $\mathbf{1}$ & $\mathbf{1 0 0}$ & $\mathbf{1 8}$ & $\mathbf{1 0 0}$ \\
\hline
\end{tabular}

Fonte: MIYASHIRO, S. F. O. (2014/2015).

Org.: MIYASHIRO, S. F. O. (2015).

Para os sem-terra, a necessidade de subsistência é considerada como um empecilho, impedindo que muitos continuem morando nos acampamentos, haja vista que a renda familiar chega ao máximo de 02 (dois) salários mínimos, conforme demonstra a Tabela $05^{4}$.

Tabela 05: Número de pessoas $\left(\mathrm{N}^{\circ}\right)$ e percentual $(\%)$ da renda familiar dos entrevistados nos acampamento Fortaleza e Renascer, Mato Grosso

\begin{tabular}{lcccccc}
\hline & \multicolumn{9}{c}{ Renda familiar } & \multicolumn{3}{c}{ TOTAL } \\
\hline Acampamento & \multicolumn{2}{c}{ Até 1 salário } & \multicolumn{1}{c}{1 a 2 salários } & $\mathrm{N}^{\mathbf{2}}$ & $\%$ \\
& $\mathrm{~N}^{\mathrm{o}}$ & $\%$ & $\mathrm{~N}^{\mathrm{o}}$ & $\%$ & 11 & 61,1 \\
Fortaleza & 6 & 54,5 & 5 & 71,4 & 7 & 38,9 \\
Renascer & 5 & 45,5 & 2 & 28,6 & $\mathbf{1 0 0}$ \\
\hline Total & $\mathbf{1 1}$ & $\mathbf{1 0 0}$ & $\mathbf{7}$ & $\mathbf{1 0 0}$ & $\mathbf{1 8}$ & $\mathbf{1 0 0}$ \\
\hline
\end{tabular}

Fonte: MIYASHIRO, S. F. O. (2014/2015).

Org.: MIYASHIRO, S. F. O. (2015).

A maior parte dos entrevistados tem renda familiar de até 01 (um) salário mínimo, ou seja, 6 entrevistados, equivalente a 54,5\% no acampamento Fortaleza e 5, equivalente a 45,5\% no acampamento Renascer, totalizando 11 entrevistados. Esta pouca renda que provém 
Territórios de vida e de esperança nos acampamentos Fortaleza e Renascer na Mesorregião Sudeste de Mato Grosso, Brasil
Shirlei Fernandes de Oliveira Miyashiro Nestor Alexandre Perehouskei

da pequena produção (venda de galinhas, ovos, porcos e outros) dentro do acampamento, gera a necessidade de buscar fora do acampamento um acréscimo financeiro, com a realização de outras atividades, tais como, funileiro, pedreiro, serviços gerais e outros. Esta variável é correspondente aos dados da Tabela 05, que expressam a baixa renda mensal dos acampados.

A sexta questão do perfil socioeconômico refere-se ao tipo de ocupação profissional dos entrevistados, conforme expressa a Tabela 06, onde verifica-se que a variável "aposentados" apresenta o maior número de entrevistados no acampamento Fortaleza, num total de 4 , equivalente a $66,6 \%$, enquanto no acampamento Renascer, o total de aposentados foi de 2 entrevistados, equivalente a 33,4\%, num total de 6 entrevistados, equivalente a 33,4\% do total de 18 entrevistados, equivalente a $100 \%$.

Representativo também, os resultados de pessoas desempregadas, perfazendo um total de 2 entrevistados, equivalente a 33,4\% no acampamento Fortaleza e 4, equivalente a $66,6 \%$, num total de 6 entrevistados, correspondendo a 33,4\% do total de 18 entrevistados, equivalente a $100 \%$. Surpreendentemente, apenas uma pessoa declarou ser do lar no acampamento Fortaleza, assim como, no acampamento Renascer, as funções de empregado e do lar não foram identificadas na pesquisa aplicada. No mesmo sentido, estes dados fazem correspondência com os dados de baixa remuneração, escolaridade e faixa etária analisados anteriormente.

Tabela 06: Número de pessoas $\left(\mathrm{N}^{\circ}\right)$ e percentual (\%) da ocupação dos entrevistados nos acampamentos Fortaleza e Renascer, Mato Grosso

\begin{tabular}{|c|c|c|c|c|c|c|c|c|c|c|c|c|}
\hline \multicolumn{13}{|c|}{ Ocupação } \\
\hline \multirow[b]{2}{*}{ Acampamento } & \multicolumn{2}{|c|}{ Empregado } & \multicolumn{2}{|c|}{ Do lar } & \multicolumn{2}{|c|}{ Desempregado } & \multicolumn{2}{|c|}{ Autônomo } & \multicolumn{2}{|c|}{ Aposentado } & \multicolumn{2}{|c|}{ TOTAL } \\
\hline & $\mathrm{N}^{\mathrm{o}}$ & $\%$ & $\mathrm{~N}^{\mathrm{o}}$ & $\%$ & $\mathrm{~N}^{\mathrm{o}}$ & $\%$ & $\mathrm{~N}^{\mathrm{o}}$ & $\%$ & $\mathrm{~N}^{\mathrm{o}}$ & $\%$ & $\mathrm{~N}^{\circ}$ & $\%$ \\
\hline Fortaleza & 2 & 100 & 1 & 100 & 2 & 33,4 & 2 & 66,6 & 4 & 66,6 & 11 & 61,1 \\
\hline Renascer & 0 & 0 & 0 & 0 & 4 & 66,6 & 1 & 33,4 & 2 & 33,4 & 7 & 38,9 \\
\hline Total & 2 & 100 & 1 & 100 & 6 & 100 & 3 & 100 & 6 & 100 & 18 & 100 \\
\hline
\end{tabular}

Fonte: MIYASHIRO, S. F. O. (2014/2015).

Org.: MIYASHIRO, S. F. O. (2015).

A sétima questão refere-se à identificação de residência no acampamento ou não, conforme apresenta a Tabela 07. 
Territórios de vida e de esperança nos acampamentos Fortaleza e Renascer na Mesorregião Sudeste de Mato Grosso, Brasil
Shirlei Fernandes de Oliveira Miyashiro Nestor Alexandre Perehouskei

Tabela 07: Número de pessoas $\left(\mathrm{N}^{\circ}\right)$ e percentual (\%) que residem ou não nos acampamentos Fortaleza e Renascer, Mato Grosso

\begin{tabular}{lrrrrrc}
\hline \multicolumn{7}{c}{ Moradia no acampamento } \\
\hline Acampamento & \multicolumn{2}{c}{ Sim } & \multicolumn{3}{c}{ Não } & \multicolumn{3}{c}{ Total } \\
\cline { 2 - 8 } Fortaleza & $\mathrm{N}^{\mathrm{o}}$ & $\%$ & $\mathrm{~N}^{\mathrm{o}}$ & $\%$ & $\mathrm{~N}^{\mathrm{O}}$ & $\%$ \\
Renascer & 6 & 60 & 5 & 62,5 & 11 & 61,1 \\
\hline Total & 4 & 40 & 3 & 37,5 & 7 & 38,9 \\
\hline
\end{tabular}

Fonte: MIYASHIRO, S. F. O. (2014/2015).

Org.: MIYASHIRO, S. F. O. (2015).

A partir dos resultados, pouco mais da metade dos entrevistados moram nos acampamentos, totalizando 10 entrevistados, enquanto os que não residem, totalizaram 8 entrevistados, morando principalmente nas cidades de Rondonópolis e Pedra Preta, portanto, moradores itinerantes nos acampamentos.

A oitava questão apresenta os motivos que levaram os entrevistados a aderirem ao movimento de sem-terra, conforme apresenta a Tabela 08.

Tabela 08: Número de pessoas $\left(\mathrm{N}^{\circ}\right)$ e percentual $(\%)$ de motivos de adesão ao movimento de sem-terra nos acampamentos Fortaleza e Renascer, Mato Grosso

\begin{tabular}{|c|c|c|c|c|c|c|c|c|}
\hline \multicolumn{9}{|c|}{ Motivos de adesão ao movimento sem-terra* } \\
\hline \multirow[t]{2}{*}{ Acampamento } & \multicolumn{2}{|c|}{$\begin{array}{l}\text { Dificuldade de } \\
\text { sobrevivência na } \\
\text { cidade }\end{array}$} & \multicolumn{2}{|c|}{ Ter um lote } & \multicolumn{2}{|c|}{ Outros } & \multicolumn{2}{|c|}{ Total } \\
\hline & $\mathrm{N}^{\mathrm{o}}$ & $\%$ & $\mathrm{~N}^{\mathrm{o}}$ & $\%$ & $\mathrm{~N}^{\mathrm{o}}$ & $\%$ & $\mathrm{~N}^{\mathrm{o}}$ & $\%$ \\
\hline Fortaleza & 3 & 100 & 9 & 56,2 & 1 & 100 & 13 & 65 \\
\hline Renascer & 0 & 0 & 7 & 43,8 & 0 & 0 & 7 & 35 \\
\hline Total & 3 & 100 & 16 & 100 & 1 & 100 & 20 & 100 \\
\hline
\end{tabular}

Fonte: MIYASHIRO, S. F. O. (2014/2015).

Org.: MIYASHIRO, S. F. O. (2015).

*Alguns entrevistados expressaram mais de uma resposta.

$\mathrm{Na}$ Tabela 08, a maioria dos entrevistados aderiu ao movimento pelo sonho em conseguir um lote de terra, representando 09 entrevistados, equivalente a 56,2\% no acampamento Fortaleza, bem como 07 entrevistados, equivalente a 43,8\% no acampamento Renascer, totalizando 16 entrevistados. Em menores porcentagens, ou seja, pouco representativo na amostra, as dificuldades de sobrevivência no meio urbano, principalmente relacionado ao desemprego e outros. 
Territórios de vida e de esperança nos acampamentos Fortaleza e Renascer na Mesorregião Sudeste de Mato Grosso, Brasil
Shirlei Fernandes de Oliveira Miyashiro Nestor Alexandre Perehouskei

A questão 09 investiga as opiniões dos entrevistados com relação à moradia de itinerantes, ou seja, as pessoas que possuem o barraco no acampamento, frequentando nos finais de semana e, paralelamente, residem na cidade.

Tabela 09: Número de pessoas $\left(\mathrm{N}^{\circ}\right)$ e percentual $(\%)$ de opiniões com relação à moradia de itinerantes nos acampamentos Fortaleza e Renascer, Mato Grosso

\begin{tabular}{lrrrrrr}
\hline \multicolumn{7}{c}{ Opinião quanto à moradia de itinerantes no acampamento } \\
\hline & \multicolumn{2}{c}{ Aceita } & \multicolumn{2}{c}{ Não aceita $^{\text {Total }}$} \\
\cline { 2 - 8 } Acampamento & $\mathrm{N}^{\mathbf{0}}$ & $\%$ & $\mathrm{~N}^{\mathbf{2}}$ & $\%$ & $\mathrm{~N}^{\mathbf{0}}$ & $\%$ \\
Fortaleza & 9 & 60 & 2 & 66,6 & 11 & 61,1 \\
Renascer & 6 & 40 & 1 & 33,4 & 7 & 38,9 \\
\hline Total & $\mathbf{1 5}$ & $\mathbf{1 0 0}$ & $\mathbf{3}$ & $\mathbf{1 0 0}$ & $\mathbf{1 8}$ & $\mathbf{1 0 0}$ \\
\hline
\end{tabular}

Fonte: MIYASHIRO, S. F. O. (2014/2015).

Org.: MIYASHIRO, S. F. O. (2015).

De acordo com as respostas, a maioria dos entrevistados concorda com esta lógica representando 09 entrevistados, equivalente a 60\% no acampamento Fortaleza, bem como 06 entrevistados, equivalente a $40 \%$ no acampamento Renascer, totalizando 15 entrevistados. Dentre os principais motivos, estão: não existem outras opções; necessidade de trabalho para o sustento da família; a procura por conforto; devido ao pouco ganho das atividades no acampamento; pela ajuda mútua; pela garantia em ter o direito de participar do sorteio de lotes, assegurando, dessa forma, o bem estar dos filhos; a contribuição para a segurança do acampamento; e alguns concordam desde que, as pessoas envolvidas nesta lógica, participem das lutas que dizem respeito ao acampamento.

Em menores porcentagens estão as pessoas que discordam desta lógica, representando 03 entrevistados. Dentre os motivos apontados pelos entrevistados, estão: quem não vive no acampamento, futuramente também não irá cuidar do lote; deveriam morar para ter direito ao lote; quem não mora não passa pelas vicissitudes dos que residem permanentemente.

A décima questão aponta as opiniões dos entrevistados quanto a opção de permanência nos acampamentos, conforme demonstra a Tabela 10. 
Territórios de vida e de esperança nos acampamentos Fortaleza e Renascer na Mesorregião Sudeste de Mato Grosso, Brasil
Shirlei Fernandes de Oliveira Miyashiro Nestor Alexandre Perehouskei

Tabela 10: Número de pessoas $\left(\mathrm{N}^{\circ}\right)$ e percentual $(\%)$ de opiniões quanto à opção de permanência nos acampamentos Fortaleza e Renascer, Mato Grosso Motivos de opção pela permanência no acampamento

\begin{tabular}{lcccccccc}
\hline \multicolumn{7}{c}{ Motivos de opção pela permanência no acampamento } \\
Acampamento & $\begin{array}{c}\text { Falta de recursos } \\
\text { para morar na } \\
\text { cidade }\end{array}$ & $\begin{array}{c}\text { Não permanecem, } \\
\text { mas vislumbram a } \\
\text { Fortaleza }\end{array}$ & $\begin{array}{c}\text { terra } \\
\mathrm{N}^{\mathbf{0}}\end{array}$ & $\begin{array}{c}\text { A relação de } \\
\text { pertencimento ao } \\
\text { campo }\end{array}$ & \multicolumn{2}{c}{ Total } \\
Renascer & 3 & 75 & 5 & 62,5 & 3 & 50 & 11 & 61,1 \\
\hline Total & 1 & 25 & 3 & 37,5 & 3 & 50 & 7 & 38,9 \\
\hline
\end{tabular}

Fonte: MIYASHIRO, S. F. O. (2014/2015).

Org.: MIYASHIRO, S. F. O. (2015).

Com os resultados obtidos, a maioria dos entrevistados não permanece constantemente nos acampamentos, no entanto, mantém o vínculo, vislumbrando a futura aquisição de um lote, correspondendo a 05 entrevistados, equivalente a $62,5 \%$ no acampamento Fortaleza, bem como 03 entrevistados, equivalente a 37,5\% no acampamento Renascer, totalizando 08 entrevistados. Esta tabela correlaciona-se à Tabela 09, onde a maior parte dos moradores que não permanecem nos acampamentos também são aceitos pelos demais do grupo, cujo maior objetivo é a futura conquista do lote.

$\mathrm{Na}$ variável que apresenta a relação de pertencimento ao campo, totalizou-se 06 entrevistados em ambos acampamentos, equivalente a 50\% em cada.

Surpreendentemente, apresentou-se em menores proporções, a variável "falta de recursos para morar na cidade".

Ao analisar a décima primeira questão com relação às dificuldades relatadas pelos entrevistados nos acampamentos, demonstram-se os dados de acordo com a Tabela 11.

Tabela 11: Número de pessoas $\left(\mathrm{N}^{\circ}\right)$ e percentual (\%) de dificuldades encontradas nos acampamentos Fortaleza e Renascer, Mato Grosso

\begin{tabular}{|c|c|c|c|c|c|c|c|c|c|c|c|c|}
\hline \multicolumn{13}{|c|}{ Dificuldades nos acampamentos* } \\
\hline \multirow[t]{2}{*}{ Acampamento } & \multicolumn{2}{|c|}{$\begin{array}{l}\text { Abastecimento } \\
\text { de água }\end{array}$} & \multicolumn{2}{|c|}{$\begin{array}{l}\text { Cesta } \\
\text { básica }\end{array}$} & \multicolumn{2}{|c|}{ Saúde } & \multicolumn{2}{|c|}{ Trabalho } & \multicolumn{2}{|c|}{ Outros } & \multicolumn{2}{|c|}{ Total } \\
\hline & $\mathrm{N}^{\mathrm{o}}$ & $\%$ & $\mathrm{~N}^{\mathrm{o}}$ & $\%$ & $\mathrm{~N}^{\mathrm{o}}$ & $\%$ & $\mathrm{~N}^{\circ}$ & $\%$ & $\mathrm{~N}^{\mathrm{o}}$ & $\%$ & $\mathrm{~N}^{\mathrm{o}}$ & $\%$ \\
\hline Fortaleza & 8 & 72,7 & 7 & 77,7 & 6 & 100 & 4 & 57,1 & 13 & 65 & 38 & 71,6 \\
\hline Renascer & 3 & 27,3 & 2 & 22,3 & 0 & 0 & 3 & 42,9 & 7 & 35 & 15 & 28,4 \\
\hline Total & 11 & 100 & 9 & 100 & 6 & 100 & 7 & 100 & 20 & 100 & 53 & 100 \\
\hline
\end{tabular}

Fonte: MIYASHIRO, S. F. O. (2014/2015).

Org.: MIYASHIRO, S. F. O. (2015).

*Alguns expressaram mais de uma resposta. 
Territórios de vida e de esperança nos acampamentos Fortaleza e Renascer na Mesorregião Sudeste de Mato Grosso, Brasil
Shirlei Fernandes de Oliveira Miyashiro Nestor Alexandre Perehouskei

$\mathrm{Na}$ análise destes resultados, a variável "Outros" foi representativa com 20 respostas, sendo 13 no acampamento Fortaleza e 7 no acampamento Renascer, dadas pelos entrevistados, devido a sua diversidade de opiniões, tais como: risco de acidentes nas estradas; a solidão; ausência de moradias; a precariedade dos barracos; ajuda de modo geral; a burocracia do Incra; a distância da cidade; o espaço inadequado para a criação de animais; o calor da lona; a presença de insetos; a impossibilidade de obter energia elétrica; a dificuldade na conservação de alimentos; dificuldade de mobilidade; a falta de segurança e a ausência de escola para as crianças.

Em menores porcentagens apresentam-se as variáveis: abastecimento de água, cesta básica, a saúde e o trabalho. Dentre elas se sobressai o abastecimento de água com 11 respostas. Esta questão se relaciona também com a presença dos itinerantes, analisadas nas Tabelas 09 e 10, pois justifica alguns dos motivos de não permanecerem nos acampamentos.

$\mathrm{Na}$ décima segunda questão avaliou-se a opinião dos entrevistados sobre a qualidade de vida urbana do sem-terra, que possui vivência também no espaço do acampamento, conforme apresenta a Tabela 12.

Tabela 12: Número de pessoas $\left(\mathrm{N}^{\circ}\right)$ e percentual $(\%)$ de opiniões sobre a qualidade de vida urbana do sem-terra nos acampamentos Fortaleza e Renascer, Mato Grosso

\begin{tabular}{|c|c|c|c|c|c|c|}
\hline \multicolumn{7}{|c|}{ Qualidade de vida urbana do sem-terra } \\
\hline \multirow{2}{*}{ Acampamento } & \multicolumn{2}{|c|}{ Melhor } & \multicolumn{2}{|c|}{ Não é melhor } & \multicolumn{2}{|c|}{ Total } \\
\hline & $\mathrm{N}^{\mathrm{o}}$ & $\%$ & $\mathrm{~N}^{\mathrm{o}}$ & $\%$ & $\mathrm{~N}^{\mathrm{o}}$ & $\%$ \\
\hline Fortaleza & 7 & 58,3 & 4 & 66,6 & 11 & 61,1 \\
\hline Renascer & 5 & 41,7 & 2 & 33,4 & 7 & 38,9 \\
\hline Total & 12 & 100 & 6 & 100 & 18 & 100 \\
\hline
\end{tabular}

Fonte: MIYASHIRO, S. F. O. (2014/2015).

Org.: MIYASHIRO, S. F. O. (2015).

Com a obtenção destes resultados percebe-se que a maioria dos entrevistados, ou seja, 7 , equivalente a 58,3\% no acampamento Fortaleza, bem com 5, equivalente a $41,7 \%$ no acampamento Renascer, totalizando 12 entrevistados, acreditam na melhor qualidade de vida, devido a ajuda das pessoas que vivem no acampamento como, por exemplo, a oferta de alimentos; consegue garantir seu cadastramento no movimento para um futuro sorteio do lote; pelo conforto da cidade; por não passar pelas mesmas necessidades do acampado e por maiores opções de trabalho.

Verificou-se em menor porcentagem, 7 entrevistados, equivalente a 33,4\%, acreditam que a qualidade de vida não melhorou, devido principalmente às seguintes 
Territórios de vida e de esperança nos acampamentos Fortaleza e Renascer na Mesorregião Sudeste de Mato Grosso, Brasil
Shirlei Fernandes de Oliveira Miyashiro Nestor Alexandre Perehouskei

questões: a perda do vínculo com o acampamento; tem o mesmo sofrimento de quem está acampado; a necessidade de mobilidade entre o acampamento e a cidade. Com os dados desta tabela, verifica-se certa ligação com a presença de itinerantes que, mesmo morando no espaço urbano, não querem perder o vínculo com as comunidades dos acampamentos.

Com relação às necessidades de mudanças no perfil da luta, foram apontadas algumas questões, conforme demonstra a Tabela 13.

Tabela 13: Número de pessoas $\left(\mathrm{N}^{\circ}\right)$ e percentual (\%) de opiniões sobre as necessidades de mudança no perfil da luta nos acampamentos Fortaleza e Renascer, Mato Grosso

\begin{tabular}{|c|c|c|c|c|c|c|c|c|c|c|}
\hline \multicolumn{11}{|c|}{ Mudanças no perfil da luta* } \\
\hline \multirow[t]{2}{*}{ Acampamento } & \multicolumn{2}{|c|}{$\begin{array}{l}\text { Apoio do Incra } \\
\text { e coordenadores }\end{array}$} & \multicolumn{2}{|c|}{$\begin{array}{l}\text { Condição de } \\
\text { saúde }\end{array}$} & \multicolumn{2}{|c|}{$\begin{array}{c}\text { Relação de } \\
\text { companheirismo }\end{array}$} & \multicolumn{2}{|c|}{ Outros } & \multicolumn{2}{|c|}{ Total } \\
\hline & $\mathrm{N}^{\mathrm{o}}$ & $\%$ & $\mathrm{~N}^{\mathrm{o}}$ & $\%$ & $\mathrm{~N}^{\mathrm{o}}$ & $\%$ & $\mathrm{~N}^{\mathrm{o}}$ & $\%$ & $\mathrm{~N}^{\mathrm{o}}$ & $\%$ \\
\hline Fortaleza & 9 & 52,9 & 1 & 33,4 & 2 & 100 & 6 & 66,6 & 18 & 58 \\
\hline Renascer & 8 & 47,1 & 2 & 66,6 & 0 & 0 & 3 & 33,4 & 13 & 42 \\
\hline Total & 17 & 100 & 3 & 100 & 2 & 100 & 9 & 100 & 31 & 100 \\
\hline
\end{tabular}

Fonte: MIYASHIRO, S. F. O. (2014/2015).

Org.: MIYASHIRO, S. F. O. (2015).

*Alguns expressaram mais de uma resposta.

A maioria das respostas no acampamento Fortaleza, corresponderam a 9, equivalente a 52,9\%, bem como 8, equivalente a $47,1 \%$ no acampamento Renascer, expressam a necessidade de maior apoio do Incra e dos coordenadores do movimento, totalizando 17 entrevistados.

A variável "Outros" foi representativa com 9 respostas, destacando as seguintes opiniões: infraestrutura do acampamento; a solidão; a presença dos chamados "pardais", que tiram proveito da estrutura dos acampamentos; o espaço inadequado do acampamento; falta de trabalho e de formação.

Em menores porcentagens apresentaram-se as variáveis "Condição de saúde" e a "Relação de companheirismo".

Ao analisar a décima quarta questão, verificou-se os dados que expressam as opiniões sobre a possibilidade de extinção dos acampamentos em geral, conforme apresenta a Tabela 14. 
Territórios de vida e de esperança nos acampamentos Fortaleza e Renascer na Mesorregião Sudeste de Mato Grosso, Brasil
Shirlei Fernandes de Oliveira Miyashiro Nestor Alexandre Perehouskei

Tabela 14: Número de pessoas $\left(\mathrm{N}^{\circ}\right)$ e percentual (\%) de opiniões sobre a extinção dos acampamentos de sem-terra

Extinção dos acampamentos

\begin{tabular}{lrrrrrc}
\hline Acampamento & \multicolumn{2}{c}{ Sim } & \multicolumn{2}{c}{ Não } & \multicolumn{2}{c}{ Total } \\
\cline { 2 - 7 } & $\mathrm{N}^{\mathrm{o}}$ & $\%$ & $\mathrm{~N}^{\mathrm{o}}$ & $\%$ & $\mathrm{~N}^{\mathrm{o}}$ & $\%$ \\
Fortaleza & 7 & 58,3 & 4 & 66,6 & 11 & 61,1 \\
Renascer & 5 & 41,7 & 2 & 33,4 & 7 & 38,9 \\
\hline Total & $\mathbf{1 2}$ & $\mathbf{1 0 0}$ & $\mathbf{6}$ & $\mathbf{1 0 0}$ & $\mathbf{1 8}$ & $\mathbf{1 0 0}$ \\
\hline
\end{tabular}

Fonte: MIYASHIRO, S. F. O. (2014/2015).

Org.: MIYASHIRO, S. F. O. (2015).

$\mathrm{Na}$ Tabela 14, a maioria dos entrevistados, correspondente a 12, acredita no fim dos acampamentos, por algumas razões, tais como: a pouca procura e adesão ao movimento; a demora para se conseguir o assentamento; acreditam que permaneçam apenas assentamentos, devido a decrescente polarização; acreditam que o acampamento irá acabar naturalmente; muitos não pretendem ir para outro movimento; pelas dificuldades enfrentadas e alguns almejam novas alternativas.

Em menores porcentagens, os que não aceitam o fim do acampamento, correspondendo a 6 entrevistados, justificando a sua opinião, por exemplo, pela acolhida dos membros do acampamento em relação às pessoas que precisam; aumento de dificuldades em morar em outro local, como o meio urbano; na sua perpetuação enquanto assentamento; outros acreditam que sempre existirão; pela própria luta e para pressionar o governo em relação a falta de apoio aos acampados.

A décima quinta questão refere-se ao desempenho das atividades dos coordenadores dos acampamentos, conforme apresenta a Tabela 15.

Tabela 15: Número de pessoas $\left(\mathrm{N}^{\circ}\right)$ e percentual $(\%)$ com relação à atuação dos coordenadores nos acampamentos Fortaleza e Renascer, Mato Grosso

\begin{tabular}{lrcrrrc}
\hline & \multicolumn{3}{c}{ Atuação dos coordenadores } \\
\hline Acampamento & \multicolumn{2}{c}{ Boa } & \multicolumn{2}{c}{ Ruim } & \multicolumn{3}{c}{ Total } \\
\cline { 2 - 8 } & $\mathrm{N}^{\mathrm{o}}$ & $\%$ & $\mathrm{~N}^{\mathrm{o}}$ & $\%$ & $\mathrm{~N}^{\circ}$ & $\%$ \\
Fortaleza & 2 & 66,6 & 9 & 60 & 11 & 61,1 \\
Renascer & 1 & 33,4 & 6 & 40 & 7 & 38,9 \\
\hline Total & $\mathbf{3}$ & $\mathbf{1 0 0}$ & $\mathbf{1 5}$ & $\mathbf{1 0 0}$ & $\mathbf{1 8}$ & $\mathbf{1 0 0}$ \\
\hline
\end{tabular}

Fonte: MIYASHIRO, S. F. O. (2014/2015).

Org.: MIYASHIRO, S. F. O. (2015).

Verificando a Tabela 15, a maioria dos entrevistados, correspondente a 15 , consideram a atuação ruim, devido a diversas situações, tais como, a demora nos informes 
Territórios de vida e de esperança nos acampamentos Fortaleza e Renascer na Mesorregião Sudeste de Mato Grosso, Brasil
Shirlei Fernandes de Oliveira Miyashiro Nestor Alexandre Perehouskei

relacionados às questões do acampamento; as dificuldades em negociação das demandas; pouca mobilização do grupo; a lentidão nas resoluções; a falta de qualificação dos representantes; pouca assistência dos coordenadores; alguns os consideram pouco participativos e outros consideram que já foi melhor; deficiência nas prestações de contas e a falta de atitude nos processos de formação do assentamento.

Foi pouco representativa a variável "Boa", com relação a atuação desses representantes, no entanto, não se apresentou qualquer justificativa para qualificá-la.

Correlacionando as Tabelas 13, 14 e 15, verifica-se que mesmo com a possibilidade de extinção dos acampamentos, grande parte dos acampados acreditam que, com o apoio do Incra e dos coordenadores do movimento, esta realidade possa se modificar.

Ao analisar a décima sexta questão, verificou-se o nível de satisfação dos acampados em relação a ação do movimento social (MTA), conforme apresenta a Tabela 16.

Tabela 16: Número de pessoas $\left(\mathrm{N}^{\circ}\right)$ e percentual $(\%)$ com relação à satisfação da ação do movimento social (MTA) nos acampamentos Fortaleza e Renascer, Mato Grosso

Ação do movimento social (MTA)

\begin{tabular}{lrrrrrrrr}
\hline \multirow{2}{*}{ Acampamento } & \multicolumn{2}{c}{ Boa } & \multicolumn{2}{c}{ Ruim } & \multicolumn{2}{c}{$\begin{array}{c}\text { Não soube } \\
\text { responder }\end{array}$} & \multicolumn{2}{c}{ Total } \\
\cline { 2 - 10 } & $\mathrm{N}^{\mathrm{o}}$ & $\%$ & $\mathrm{~N}^{\mathrm{o}}$ & $\%$ & $\mathrm{~N}^{\circ}$ & $\%$ & $\mathrm{~N}^{\circ}$ & $\%$ \\
Fortaleza & 8 & 57,1 & 3 & 100 & 0 & 0 & 11 & 61,1 \\
Renascer & 6 & 42,9 & 0 & 0 & 1 & 100 & 7 & 38,9 \\
\hline Total & $\mathbf{1 4}$ & $\mathbf{1 0 0}$ & $\mathbf{3}$ & $\mathbf{1 0 0}$ & $\mathbf{1}$ & $\mathbf{1 0 0}$ & $\mathbf{1 8}$ & $\mathbf{1 0 0}$ \\
\hline
\end{tabular}

Fonte: MIYASHIRO, S. F. O. (2014/2015).

Org.: MIYASHIRO, S. F. O. (2015).

Com estes resultados, a maioria dos entrevistados, correspondente a 14, consideram que o movimento MTA apresenta uma boa ação, por serem organizados, não serem "baderneiros", auxiliam nas manifestações, são honestos, respeitam as leis e trabalham em benefício dos acampados. Alguns consideram que o próprio movimento é que determina a existência dos acampamentos e outro acreditam que o movimento precisaria de maior apoio do Incra. Em menores porcentagens, consideram a atuação ruim ou não souberam responder, ou acreditam que o movimento não possui força no Incra e que já foi mais atuante.

A Tabela 17 demonstra o tempo de participação dos entrevistados nos movimentos sociais como membro do acampamento. 
Territórios de vida e de esperança nos acampamentos Fortaleza e Renascer na Mesorregião Sudeste de Mato Grosso, Brasil
Shirlei Fernandes de Oliveira Miyashiro Nestor Alexandre Perehouskei

Tabela 17: Número de pessoas $\left(\mathrm{N}^{\circ}\right)$ e percentual $(\%)$ de participação em movimento social nos acampamentos Fortaleza e Renascer, Mato Grosso

\begin{tabular}{|c|c|c|c|c|c|c|c|c|c|c|c|c|}
\hline \multicolumn{13}{|c|}{ Tempo (em anos) de participação no movimento social } \\
\hline \multirow[b]{2}{*}{ Acampamento } & \multicolumn{2}{|c|}{1 ano } & \multicolumn{2}{|c|}{2 anos } & \multicolumn{2}{|c|}{4 anos } & \multicolumn{2}{|c|}{5 anos } & \multicolumn{2}{|c|}{7 anos } & \multicolumn{2}{|c|}{ Total } \\
\hline & $\mathrm{N}^{\circ}$ & $\%$ & $\mathrm{~N}^{\circ}$ & $\%$ & $\mathrm{~N}^{\circ}$ & $\%$ & $\mathrm{~N}^{\circ}$ & $\%$ & $\mathrm{~N}^{\circ}$ & $\%$ & $\mathrm{~N}^{\circ}$ & $\%$ \\
\hline Fortaleza & 1 & 100 & 0 & 0 & 1 & 100 & 4 & 100 & 5 & 100 & 11 & 61,1 \\
\hline Renascer & 0 & 0 & 7 & 100 & 0 & 0 & 0 & 0 & 0 & 0 & 7 & 38,9 \\
\hline Total & 1 & 100 & 7 & 100 & 1 & 100 & 4 & 100 & 5 & 100 & 18 & 100 \\
\hline
\end{tabular}

Fonte: MIYASHIRO, S. F. O. (2014/2015).

Org.: MIYASHIRO, S. F. O. (2015).

De acordo com os resultados obtidos, a maioria dos entrevistados no acampamento Fortaleza participam do movimento social durante o período de 5 e 7 anos, correspondente a 9 entrevistados, tendo relação direta com o tempo de existência do acampamento. No acampamento Renascer, 7 entrevistados, ou seja, o total da amostra, participam durante 2 anos no movimento, que é o tempo de existência do acampamento.

Pode-se notar pela Tabela 18 os resultados referentes às opiniões dos entrevistados quanto a perspectivas de mudança de vida nos acampamentos.

Tabela 18: Número de pessoas $\left(\mathbf{N}^{\circ}\right)$ e percentual $(\%)$ de opiniões quanto às perspectivas de mudança de vida nos acampamentos Fortaleza e Renascer, Mato Grosso

\begin{tabular}{lrrrrrr}
\hline & \multicolumn{3}{c}{ Perspectivas de mudança de vida } \\
\hline Acampamento & \multicolumn{2}{c}{ Sim } & \multicolumn{2}{c}{ Não } & \multicolumn{3}{c}{ Total } \\
\cline { 2 - 8 } & $\mathrm{N}^{\mathrm{o}}$ & $\%$ & $\mathrm{~N}^{\mathrm{o}}$ & $\%$ & $\mathrm{~N}^{\mathrm{o}}$ & $\%$ \\
Fortaleza & 11 & 61,1 & 0 & 0 & 11 & 61,1 \\
Renascer & 7 & 38,9 & 0 & 0 & 7 & 38,9 \\
\hline Total & $\mathbf{1 8}$ & $\mathbf{1 0 0}$ & $\mathbf{0}$ & $\mathbf{0}$ & $\mathbf{1 8}$ & $\mathbf{1 0 0}$ \\
\hline
\end{tabular}

Fonte: MIYASHIRO, S. F. O. (2014/2015).

Org.: MIYASHIRO, S. F. O. (2015).

De acordo com os resultados, apesar de todas as dificuldades existentes no universo dos acampamentos, surpreendentemente, o total da amostra apresentou perspectivas positivas de mudança de vida, quando da criação do assentamento que representará a conquista do território definitivo; ao conseguirem o lote, apesar de toda a demora e burocracia; são pessoas que buscam realizar seus sonhos, na espera de um futuro melhor.

\section{Considerações finais}

Durante o processo de construção desta pesquisa, buscou-se definir os objetivos, a escolha do método e a questão-problema que direcionaram a investigação, pautados na escolha do universo do acampamento de sem-terra. 
De acordo com os resultados da presente pesquisa, a maioria dos entrevistados é do sexo masculino, em razão de haver uma preocupação com a segurança do acampamento e ocupação diária no trabalho para a garantia de subsistência, pressupondo a presença masculina, no sentido de imposição em relação à ocupação do lugar.

Verificou-se o predomínio de pessoas na faixa-etária de 31 a 60 anos, ou seja, que ainda se encontram em fases de vida produtiva.

Analisando o grau de escolaridade, constatou-se que a maioria dos entrevistados estudou no máximo até a $4^{\mathrm{a}}$ série do atual primeiro ciclo do ensino fundamental. Apesar de pouca escolaridade, são pessoas que trazem como experiência, a vivência e a luta como sinônimos de saber.

Quanto ao número de pessoas por família dos entrevistados, prevalecem as famílias de 2 a 5 pessoas. Neste universo apresentaram-se famílias com duas a três pessoas, compostas pelo avô, a avó e um neto.

A maior parte dos entrevistados tem renda familiar de 01 (um) salário mínimo, que provém da pequena produção (venda de galinhas, ovos, porcos e outros) dentro do acampamento, gerando a necessidade de buscar fora do acampamento um acréscimo financeiro, com a realização de outras atividades, tais como, funileiro, pedreiro, serviços gerais e outros.

Com relação ao tipo de ocupação profissional a maior parte dos entrevistados é constituída de aposentados.

Ao analisar a identificação de residência no acampamento ou não, mais da metade dos entrevistados moram nos acampamentos, enquanto os que não residem, moram principalmente nas cidades de Rondonópolis e Pedra Preta, portanto, são moradores itinerantes nos acampamentos.

Em referência aos motivos que levaram os entrevistados a aderirem ao movimento de sem-terra, a maioria dos entrevistados expressa que foi devido ao sonho em conseguir um lote de terra.

Quanto às opiniões dos entrevistados relacionadas à moradia de itinerantes, ou seja, as pessoas que possuem o barraco no acampamento, frequentando nos finais de semana e, paralelamente, residem na cidade, a maioria dos entrevistados concorda com esta lógica, principalmente, por não existirem outras opções; pela necessidade de trabalho para o sustento da família; a procura por conforto; devido ao pouco ganho das atividades no acampamento; 
pela ajuda mútua; pela garantia em ter o direito de participar do sorteio de lotes, assegurando, dessa forma, o bem estar dos filhos; a contribuição para a segurança do acampamento; e alguns concordam desde que, as pessoas envolvidas nesta lógica, participem das lutas que dizem respeito ao acampamento.

Sobre a permanência de pessoas nos acampamentos, a maioria dos entrevistados relatou não permanecer constantemente, no entanto, mantém o vínculo, vislumbrando a futura aquisição de um lote.

Entre as dificuldades sofridas nos acampamentos, os entrevistados demonstraram diversas situações, tais como, o risco de acidentes nas estradas; a solidão; ausência de moradias; a precariedade dos barracos; ajuda de modo geral; a burocracia do Incra; a distância da cidade; o espaço inadequado para a criação de animais; o calor da lona; a presença de insetos; a impossibilidade de obter energia elétrica; a dificuldade na conservação de alimentos; dificuldade de mobilidade; a falta de segurança e a ausência de escola para as crianças.

Nas opiniões dos entrevistados sobre a qualidade de vida urbana do sem-terra, que possui vivência também no espaço do acampamento, a maioria acredita na melhoria de qualidade de vida devido, principalmente, às seguintes questões: com a ajuda das pessoas que vivem no acampamento como, por exemplo, a oferta de alimentos; consegue garantir seu cadastramento no movimento para um futuro sorteio do lote; pelo conforto da cidade; por não passar pelas mesmas necessidades do acampado e por maiores opções de trabalho.

Quanto às necessidades de mudanças no perfil da luta, a maioria das respostas expressam a necessidade de maior apoio do Incra e dos coordenadores do movimento; melhor infraestrutura do acampamento; a presença dos chamados "pardais", que tiram proveito da estrutura dos acampamentos; o espaço inadequado do acampamento; falta de trabalho e de formação; e a solidão de alguns membros.

Com relação às opiniões sobre a possibilidade de extinção dos acampamentos em geral, a maioria dos entrevistados acredita no fim dos acampamentos, por algumas razões, tais como, a pouca procura e adesão ao movimento; a demora para se conseguir o assentamento; acreditam que permaneçam apenas assentamentos, devido a decrescente polarização; acreditam que o acampamento irá acabar naturalmente; muitos não pretendem ir para outro movimento; pelas dificuldades enfrentadas e alguns almejam novas alternativas. 
Em menores porcentagens, os que não aceitam o fim do acampamento, por algumas razões, tais como, a acolhida dos membros do acampamento em relação às pessoas que precisam; aumento de dificuldades em morar em outro local, como o meio urbano; na sua perpetuação enquanto assentamento; outros acreditam que sempre existirão; pela própria luta e para pressionar o governo em relação à falta de apoio aos acampados.

No desempenho das atividades dos coordenadores dos acampamentos, a maioria dos entrevistados, considera a atuação ruim, devido à demora nos informes relacionados às questões do acampamento; as dificuldades em negociação das demandas; pouca mobilização do grupo; a lentidão nas resoluções; a falta de qualificação dos representantes; pouca assistência dos coordenadores; alguns os consideram pouco participativos e outros consideram que já foi melhor; deficiência nas prestações de contas e a falta de atitude nos processos de formação do assentamento.

Ao analisar a satisfação dos acampados em relação a ação do movimento social MTA, a maioria dos entrevistados consideram uma boa ação, por serem organizados, não serem "baderneiros", auxiliam nas manifestações, são honestos, respeitam as leis e trabalham em benefício dos acampados. Alguns consideram que o próprio movimento é que determina a existência dos acampamentos e outro acreditam que o movimento precisaria de maior apoio do Incra.

$\mathrm{Na}$ identificação do tempo de participação dos entrevistados nos movimentos sociais como membro do acampamento, a maioria já participa do movimento social há 5 e 7 anos, tendo relação direta com o tempo de existência do acampamento.

Nas prospecções de mudanças de vida, a maioria apresentou perspectivas positivas a partir da criação do assentamento; ao conseguirem o lote, apesar de toda a demora e burocracia; são pessoas que buscam realizar seus sonhos, na espera de um futuro melhor.

Não basta apenas conquistar a terra, é preciso que o novo assentado tenha subsídios para que possa alcançar boas condições de vida, e, assim, vislumbrar a terra como lugar de vida e de trabalho, ou seja, o seu lugar de identidade.

O objetivo de se conseguir um lote é um processo que envolve toda a família e faz do acampamento um lugar único, ou seja, um "Território de Esperança". Assim, a ideia de posse da terra representa a possibilidade de se ter onde morar, produzir e garantir a subsistência familiar. 
Territórios de vida e de esperança nos acampamentos Fortaleza e Renascer na Mesorregião Sudeste de Mato Grosso, Brasil
Shirlei Fernandes de Oliveira Miyashiro Nestor Alexandre Perehouskei

Portanto, o conceito de "Territórios de Esperança", aplica-se ao acampamento, por ser um território dinâmico, de vivências, de criações, de redefinições e de delimitações, ou seja, um território inacabado, sujeito a transformações.

Por fim, o acampamento se caracteriza como um território provisório com vida e esperança, pois, mesmo acreditando na extinção dos acampamentos, trazem consigo a história, a vivência, os anseios, as alegrias e as vicissitudes de um grupo social e, a esperança de uma vida melhor na concretização do território definitivo, como assentamento, que representará a efetiva transformação social.

\section{Notas}

${ }^{1} \mathrm{O}$ acampamento constitui o lugar de organização e aglutinação de um grupo "sem terra". Ocorre em áreas menos litigiosas, "negociáveis" (beira de estradas, fazendas cedidas pelo INCRA, áreas vizinhas a assentamentos, etc). A ocupação por sua vez, corresponde ao movimento de enfrentamento com o proprietário da terra. Ocupada a terra, o proprietário reivindica seu direito à propriedade através do instrumento jurídico da reintegração de posse. Esta, se concedida pelo juiz, pode implicar mobilização da força pública para o despejo dos ocupantes.

${ }^{2}$ Ver também SCHWARZ, R. G. Terra do Trabalho, Terra de Negócios. São Paulo: LTr., 2014.

${ }^{3}$ SANTOS, M. Território e Sociedade. São Paulo: Fundação Perseu Abramo, 2009, p. 46.

${ }^{4}$ Valor do salário mínimo em setembro de 2015: R\$ 788,00.

${ }^{5}$ Os "pardais", também chamados de "andorinhas", referem-se aos moradores itinerantes nos acampamentos.

\section{Referências}

ARAÚJO, L. H. A. Questão fundiária na ordem social. Porto Alegre: Movimento, 1985.

BERGAMASCO, S. M. P.; NORDER, L. A. C. A alternativa dos assentamentos rurais: organização social, trabalho e política. São Paulo: Terceira Margem, 2003.

BIROLI, F. Autonomia e desigualdades de gênero: contribuições do feminismo para a crítica democrática, Anuário Antropológico [Online]. Disponível em:

$<$ http://aa.revues.org/717>. Acesso: 15 nov. 2014.

BRASIL. DNIT. Dados para mapeamento dos municípios do estado do Mato Grosso.

Disponível em: <http://www.dnit.gov.br/>. Acesso em: 19 fev. 2015.

IBGE. Dados para mapeamento dos municípios do estado do Mato Grosso.

Disponível em: <http://www.ibge.gov.br/home>. Acesso em: 17 fev. 2015. 
Territórios de vida e de esperança nos acampamentos Fortaleza e Renascer na Mesorregião Sudeste de Mato Grosso, Brasil
Shirlei Fernandes de Oliveira Miyashiro Nestor Alexandre Perehouskei

CALLAI, H. C. Estudar o lugar para compreender o mundo. In: CASTROGIOVANNI, A. C. (Org.). Ensino de Geografia. Práticas e textualizações no cotidiano. Porto Alegre: Mediação, 2000, $173 \mathrm{p}$.

DUQUÉ, G.; CANIELLO, M. Agrovila ou casa no lote: A questão da moradia nos assentamentos da reforma agrária no Cariri paraibano. Revista econômica do Nordeste, Fortaleza v. 37, n 4, 2006. Disponível em:

$<$ www.bnb.gov.br/projwebren/Exec/artigoRenPDF.aspx?cd_artigo_ren=383>. Acesso em: 20 jan. 2014.

FERNANDES, B. M. Contribuição ao estudo do campesinato: formação e territorialização dos movimentos dos trabalhadores rurais sem-terra - MST (1979-1999). 1999. Tese (Doutorado em Geografia) - Faculdade de Filosofia, Letras e Ciências Humanas da Universidade de São Paulo, São Paulo, 1999.

. Entrando nos territórios do Território. In: PAULINO, E. T.; FABRINI, J. E. Campesinato e territórios em disputa. São Paulo: Expressão Popular, 2008.

Territórios da questão agrária: campesinato, reforma agrária e agronegócio. Reforma Agrária, v. 34, n. 2, 2007.

GANCHO, C. V.; LOPES, H. Q. F.; TOLEDO, V. V. A Posse da terra. São Paulo: Ática, 1991.

HARVEY, D. Espaços de Esperança. São Paulo: Edições Loyola, 2009.

HEIDRICH, A. L. et al. A itinerância e o acampamento, condição e situação para o ensino de Geografia no MST”. In: REGO, N.; SUERTEGARAY, D; HEIDRICH, A. L. (Org.).

Geografia e educação: geração de ambiências. Porto Alegre: Editora da UFRGS, 2000.

MARTINS, J. S. Os camponeses e a política no Brasil. Petrópolis: Vozes, 1981.

MOREIRA, E. Território(s) de esperança: projeto de pesquisa. João Pessoa: CNPq, 2006.

MOREIRA, E; TARGINO, I. De território de exploração a território de esperança: organização agrária e resistência camponesa no semi-árido paraibano. Revista Nera, n. 10, 2007.

OLIVEIRA, A. U. A geografia das lutas no campo. São Paulo: Contexto, 1988.

RAFFESTIN, C. Por uma Geografia do poder. São Paulo: Ática, 1980.

RELPH, E. C. As bases fenomenológicas da Geografia. Geografia, v. 4, n. 7, 1979.

ROCHA, H. F. Produção territorial das reformas agrárias no Brasil. Dissertação (Mestrado em Geografia). Programa de Pós-Graduação em Geografia da Universidade Estadual Paulista, campus de Presidente Prudente. Universidade Estadual Paulista, 2013.

CAMPO-TERRITÓRIO: revista de geografia agrária, v. 11, n. 22, p. 341-370, abr., 2016 
Territórios de vida e de esperança nos acampamentos Fortaleza e Renascer na Mesorregião Sudeste de Mato Grosso, Brasil
Shirlei Fernandes de Oliveira Miyashiro Nestor Alexandre Perehouskei

SANTOS, M. Sociedade e espaço. São Paulo: AGB, 1977.

. Território e Sociedade: entrevista com Milton Santos. São Paulo: Editora Fundação Perseu Abramo, 2009.

SCHWARZ, R. G. Terra do Trabalho, Terra de Negócios. São Paulo: LTr, 2014.

SOUZA. M. J. L. O território: sobre espaço e poder, autonomia e desenvolvimento. In:

CASTRO, I. E.; GOMES, P. C. C.; CORREAA; R. L. (Orgs.). Geografia: conceitos e temas. Rio de Janeiro: Bertrand Brasil, 2005.

STÉDILE, J. P. A Questão Agrária no Brasil. São Paulo: Atual, 1997.

SUERTEGARAY, D. M. A. Espaço geográfico uno e múltiplo. Revista electrónica de geografía y ciencias sociales. N. 93, 15 de julio de 2001. Disponível em:

$<$ http://www.ub.edu/geocrit/nova.htm> Acesso em 20 jul. 2015.

TUAN, Y. Espaço e lugar: a perspectiva da experiência. São Paulo: Difel, 1983.

VENDRAMINI, C. R. Educação em movimento na luta pela terra. Florianópolis: VerusRecord, 2002. 